\title{
MARRUECOS: LOS RETOS DE UNA DEMOCRACIA NACIENTE
}

\author{
MOROCCO: CHALLENGES FOR A NEWLY BORN DEMOCRACY
}

\author{
Mohamed Boundi Boundi \\ Sociólogo y Periodista, Madrid. España/Spain \\ mboundi@yahoo.fr
}

Recibido/Received: 06/04/08

Aceptado/Accepted: 21/07/08

\section{RESUMEN}

El sistema político de Marruecos padece un enorme retraso en la aplicación de las reformas democráticas. Sin mayoría en el Parlamento, el actual gobierno de coalición es incapaz de asumir plenamente el poder ejecutivo. Como las elecciones legislativas de septiembre de 2007 no resolvieron esta incógnita, el islamista Partido de Justicia y Desarrollo sigue cobrando fuerza como alternativa de poder.

\section{PALABRAS CLAVE}

Monarquía, partidos, parlamento, elecciones, reformas.

\section{ABSTRACT}

The legislative elections on September 2007 didn't resolve the unknowns about the Morocco's political system that suffers from a large lag in the democratic reforms. Without Parliamentary majority, the current government of coalition is unable to assume completely the executive power. Now, the Party of Justice and Development (Islamist) goes on getting force as alternative power.

\section{KEYWORDS}

Monarchy, parties, parliament, elections, reforms.

\section{INTRODUCCIÓN}

Marruecos es un país que padece un verdadero déficit en lo que a cultura política se refiere. Numerosas preguntas se han quedado sin respuesta después de las últimas elecciones legislativas del 7 de septiembre de 2007, las segundas del reinado de Mohamed VI, dado el alto porcentaje de abstención (63\%), preguntas a las que además se han sumado otras nuevas surgidas a raíz del nombramiento del Primer Ministro. Con tan sólo el $18 \%$ de votantes reales, nos preguntamos si es que el proceso de transición democrática que se puso en marcha en 1998 está 
atascado o es que la sociedad está harta de discursos políticos nada acordes con sus expectativas.

A pesar de este pobre resultado electoral, el Rey nombró como Primer Ministro a Abès Fasí, líder del Istiqlal, el partido más votado (52 escaños). Fasí es el personaje menos esperado para dirigir grandes funciones ejecutivas en el gobierno, coordinar la acción política o compartir el poder ejecutivo con el monarca. Exceptuando al partido Istiqlal, no existe nadie conforme con este nombramiento, incluso la prensa independiente considera que esta decisión es "la peor derrota para la democracia"1. ¿Cómo funciona el poder político en Marruecos? ¿Habrá un nuevo mapa político después del 7 de septiembre? ¿Qué tipo de gobierno merecerá el país?

\section{LA MONARQUÍA Y EL ESPÍRITU DE LAS LEYES}

En el centro del sistema político marroquí se encuentra el Rey, heredero de una dinastía de más de cuatro siglos ${ }^{2}$, que es, según la Constitución, Jefe Supremo de las Fuerzas Armadas, dotado de numerosas atribuciones ejecutivas, del poder legislativo y, al mismo tiempo es Amir al Muminin (Príncipe o Comendador de los creyentes), la alta jerarquía eclesiástica en el Islam pero no reconocida fuera de Marruecos (Waterbury, 1975). Al apropiarse de este título ficticio, el concepto de Estado-Nación se atenúa en la concentración de poderes en una sola persona. Maneja también el "cuarto poder", gracias a las altas multas y penas de cárcel previstas en el Código de prensa ${ }^{3}$, que protege la vida privada de los miembros de la familia real, prohíbe el comentario de los discursos del monarca o la publicación sin permiso previo de informaciones relacionadas con la monarquía.

Durante los distintos procesos electorales, "domina la manipulación, la presión sobre los electores" (García López, 2000: 17). Las elecciones, organizadas desde 1960 hasta 2002, no permiten extraer auténticas radiografías del pulso político del país, pero su seguimiento permite una aproximación al complejo proceso de creación de un Marruecos político virtual, compuesto por la suma de la intervención del Ministerio de Interior en todo el proceso electoral, la participación ciudadana, el pugilato de los partidos, las concesiones del sistema y la presencia de actores locales disfrazados tras las siglas de los partidos.

Por su doble calidad de Rey y Comendador de los creyentes (Tozy, 2000:79), el monarca en Marruecos concentra en su persona tanto el poder temporal como el espiritual, por lo que el islamismo no afectaba a Marruecos de igual manera que a Argelia y Túnez, hasta que sucedieron los atentados terroristas del 16 de mayo de 2003 en Casablanca ${ }^{4}$. El islamismo reviste en general un carácter más corporativo que político ${ }^{5}$. Las autoridades controlan las mezquitas y las asociaciones más representativas centralizan su esfuerzo en las acciones sociales y caritativas. El Partido de la Justicia y del Desarrollo (PJD: 46 
diputados) ${ }^{6}$, el segundo grupo parlamentario, no se identifica con la doctrina radical de los movimientos islamistas del resto del mundo árabe-musulmán.

Toda la doctrina política oficial y el estatuto del Estado de Marruecos quedan definidos formalmente en el preámbulo y el art. 1 de su Constitución:

Preámbulo: "El Reino de Marruecos, Estado musulmán soberano, cuya lengua oficial es el árabe, constituye una parte del Gran Magreb Árabe. Siendo un Estado africano, se ha fijado además, como uno de sus objetivos, la realización de la Unidad Africana. Consciente de la necesidad de colocar su acción en el marco de los organismos internacionales, en el que se integra como miembro activo y dinámico, el Reino de Marruecos subscribe los principios, derechos y obligaciones que emanan de las cartas de dichos organismos y reafirma su adhesión a los Derechos Humanos tal como son universalmente reconocidos. Además, el Reino de Marruecos reafirma su determinación de obrar por el mantenimiento de la paz y la seguridad en el Mundo."

Artículo primero: "Marruecos es una Monarquía constitucional, democrática y social."

Los términos que aparecen en estos dos textos son similares a los que se encuentran en todas las constituciones de las viejas democracias así como en la española. La gran diferencia se hace notar en la manera de ejercer el poder y definir las prerrogativas del Rey como Jefe del Estado. El monarca no sólo nombra al Primer Ministro sino que también pone fin a sus funciones y a las del resto de los miembros de su gobierno ${ }^{7}$. Marruecos es, al final, una monarquía constitucional y no parlamentaria.

\section{DIAGNÓSTICO DE UNOS COMICIOS NO CONCLUYENTES}

En total, votaron sólo 4.700.000 de los 15.500 .000 inscritos en el censo electoral. Además, se contabilizó un millón de votos nulos (19\%), lo que al final deja una participación real del $18 \%$ y un total neto de 3,7 millones de votos expresados por una población de 33 millones de habitantes ${ }^{8}$. Los más de tres millones de inmigrantes en el extranjero han sido excluidos de la cita del 7 de septiembre. Finalmente, con estos datos, la Cámara Baja (325 diputados) representa únicamente al $10 \%$ de la población. El dato oficial más llamativo en las elecciones de septiembre de 2007 es sin lugar a dudas, el alto porcentaje de abstención, el cual roza el $63 \%$ (contra el $52 \%$ en las elecciones pasadas de septiembre de 2002). Dato que arroja un resultado pésimo: solamente acudió a las urnas el $37 \%$ de la población con derecho a voto, aunque algunas formaciones políticas afirmaban que tan sólo habían votado el $22 \%$ de marroquíes ${ }^{9}$. 
Tabla 1. Resultados oficiales de las elecciones legislativas del 7 de septiembre de 2007

\begin{tabular}{|c|c|c|}
\hline Partidos & $\begin{array}{l}\text { Número de } \\
\text { escaños }\end{array}$ & $(\%)$ \\
\hline PARTIDO DE ISTIQLAL - PI & 52 & 16 \\
\hline PARTIDO DE LA JUSTICIA Y DEL DESARROLLO - PJD & 46 & 14,15 \\
\hline MOVIMIENTO POPULAR - MP & 41 & 12,62 \\
\hline $\begin{array}{l}\text { AGRUPACIÓN NACIONAL DE LOS INDEPENDIENTES - } \\
\text { RNI }\end{array}$ & 39 & 12 \\
\hline UNIÓN SOCIALISTA DE LAS FUERZAS POPULARES - USFP & 38 & 11,69 \\
\hline UNIÓN CONSTITUCIONAL -UC & 27 & 8,31 \\
\hline PARTIDO DEL PROGRESO Y DEL SOCIALISMO - PPS & 17 & 5,23 \\
\hline FRENTE DE LAS FUERZAS DEMOCRÁTICAS - FFD & 9 & 2,77 \\
\hline MOVIMIENTO DEMOCRÁTICO Y SOCIAL - MDS & 9 & 2,77 \\
\hline $\begin{array}{l}\text { PARTIDO NACIONAL DEMOCRÁTICO IAJAHD } \\
\text { PND/ALAHD }\end{array}$ & 9 & 2,77 \\
\hline SIN AFILIACIÓN POLÍTICA - SAP & 5 & 1,54 \\
\hline PARTIDO SOCIALISTA UNIFICADO - PADS/CNI/PSU & 6 & 1,85 \\
\hline PARTIDO DE LA REFORMA Y DEL DESARROLLO - PED & 5 & 1,54 \\
\hline PARTIDO OBRERO - PT & 5 & 1,54 \\
\hline PARTIDO DE LA RENOVACIÓN Y DE LA EQUIDAD - PRE & 4 & 1,23 \\
\hline PARTIDO NACIONAL DEMOCRÁTICO - PND & 2 & 0,62 \\
\hline PARTI AL AHD - ALAHD (EL PACTO) & 3 & 0,92 \\
\hline UNIÓN MARROQUÍ POR LA DEMOCRACIA - UMD & 2 & 0,62 \\
\hline PARTIDO SOCIALISTA - PS & 2 & 0,62 \\
\hline ALIANZA DE LAS LIBERTAD - ADL & 1 & 0,31 \\
\hline $\begin{array}{l}\text { PARTIDO DEL MEDIO AMBIENTE Y DEL DESARROLLO - } \\
\text { PRV }\end{array}$ & 1 & 0,31 \\
\hline PARTIDO DE LAS FUERZAS CIUADANAS - PFC & 1 & 0,31 \\
\hline INICIATIVA CIUDADANA POR EL DESARROLLO - ICD & 1 & 0,31 \\
\hline
\end{tabular}

Ministère de l'Intérieur - Elections Législatives 2007

(Traducción propia de las denominaciones de los partidos) 
Tabla 2. Reparto porcentual de los votos en los comicios del 7 de septiembre de 2007

\section{Reparto de escaños por partido}

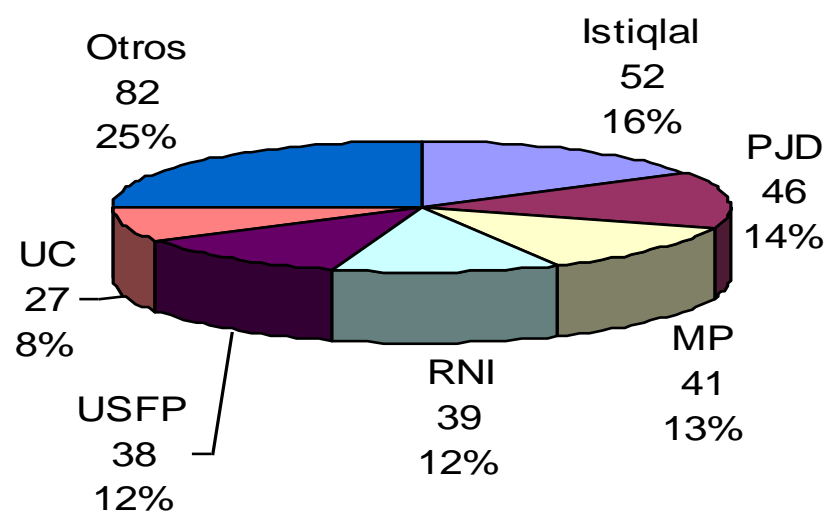

El panorama electoral se ha quedado muy fragmentado y ninguno de los 33 partidos que concurrieron a las elecciones consiguió el 20\% de los votos, de manera que a Abès Fasí le bastó con conseguir 5.642 votos para ser elegido en su circunscripción, y posteriormente llamado por el Rey para formar un gabinete. Cinco listas han cosechado más de 15.000 votos cada una y en algunos casos la mayoría de las listas reunieron entre 5.000 y 9.000 votos en sus respectivas circunscripciones. Seis partidos congregaron el 75\% de los votos, tres de entre ellos forman parte de la actual coalición gubernamental (Tabla 1).

Además del poco interés que despiertan los comicios, tampoco podemos decir que los líderes de los partidos gozaran de una gran popularidad durante estas elecciones. Citamos los más resaltados:

Saadine Otmani (PJD - islamista) obtuvo 9.533 votos $(6,32 \%)$ en un total de 150.945 inscritos en su circunscripción de Hay Hasani en Casablanca.

Abès Fasí (Al Istiqlal: conservador): consiguió 5.642 votos $(2,55 \%)$ en un total de 221.161 inscritos en la circunscripción de Larache (Norte).

Mohand Laensar (MP - rural): 12.036 votos en la circunscripción de Boulemane (Centro).

Mansuri (RNI - notables): 10.818 votos en Nador (Norte). Ismael Alaui (PPS - comunista): 4.282 votos (no elegido). 
Mohamed El Yazghi (USFP - socialista): no se presentó.

La representación en la Cámara Baja de la actual coalición gubernamental (Al Istiqlal, USFP, PPS, RNI), no dispone de la mayoría (se consigue con 176 escaños) por disponer únicamente de 127 diputados (Tabla 2), elegidos por 1.598.548 (34,6\% del total de los votos escrutados). Le faltarían 41 escaños para llegar a una mayoría cómoda, necesaria para el funcionamiento normal de la Cámara. Sin embargo, el grupo parlamentario "Tradición y Modernidad" formado por 36 diputados del entorno de Fuad Ali Al Hima, ex Ministro Delegado del Interior, representa una garantía para la estabilidad de la coalición gubernamental y una mayoría parlamentaria estable ${ }^{10}$. Como en legislaturas anteriores, el fenómeno de la "trashumancia política" se ha apoderado del parlamento marroquí y ha permitido el transvase de 33 diputados de distintos partidos administrativos al recién nacido grupo parlamentario de Al Hima. Con la perspectiva de futuros comicios, este grupo se está labrando el camino para convertirse en un nuevo partido de corte monárquico que optaría por una doctrina favorable al actual estatuto del monarca.

La apatía que caracterizó el día de la votación se explica por una serie de motivos. Recapitulamos los más significativos:

- El sistema electoral por lista, introducido por primera vez durante las elecciones de septiembre de 2002, impide una mayoría clara debido al fenómeno de escisiones dentro de los partidos. Es una fórmula calcada del sistema electoral español elaborado durante la transición, a través de un acuerdo entre los aperturistas de Manuel Fraga y los reformistas de Adolfo Suárez (Castro, 2008: 37).

- Numerosos partidos compiten por los mismos valores; además las personas votan en Marruecos por la persona y no por el partido debido al arraigo del espíritu de lealtad a las alianzas tribales, corporativas y profesionales en la sociedad (Leveau, 1976).

- El electorado ha perdido fe y confianza en los líderes políticos después de diez años de gobierno de alternancia. Alejados de las masas, los partidos que formaban la antigua coalición gubernamental fueron eclipsados por el dinamismo del Rey que dirige en persona el proceso de reformas, los proyectos socioeconómicos y monopoliza el espacio mediático.

- Los poderes del Gobierno y del Parlamento están muy limitados y encajonados en comparación con las amplias prerrogativas del Monarca. Para la población, las elecciones carecen de utilidad ante el cúmulo de poderes en la figura del Rey y la incapacidad de los políticos y diputados de reivindicar la reforma de la Constitución, la reducción de las atribuciones del monarca o una verdadera separación de los poderes.

- La necesidad de un proceso regeneracional de las cúpulas de los partidos para incitar a los jóvenes, que no vivieron ni la lucha por la independencia 
ni la pugna de la izquierda con el palacio, a tomar protagonismo en la transición política.

- La pérdida de credibilidad de los partidos tradicionales ante las crecientes ansias de mejora del poder adquisitivo que expresaban unas amplias capas sociales y la política anti-popular aplicada por el gobierno de coalición en materia socio-educativa y económica.

- La preeminencia del nepotismo, el favoritismo y el factor familiar en el seno de los partidos, tanto en la confección de las listas electorales y el reparto de carteras ministeriales, con en la designación de altos funcionarios (directores generales de empresas públicas, embajadores, representantes en organismos internacionales, rectores de universidad, etc.), condujeron a la indiferencia de las masas ante la lucha por el poder.

La alta abstención refleja el malestar de la población que se ha acostumbrado a pensar que el Rey hace todo. Cada día sigue en los telediarios de las dos cadenas nacionales ${ }^{11}$ las ceremonias de inauguración por el soberano de proyectos socio económicos en distintas regiones del país, dirigiendo consejos de ministros o nombrando a altos cargos de la administración pública.

\section{NO HUBO MAREA VERDE}

El PJD, víctima de una extrema euforia a causa de los sondeos de varios institutos americanos que le presentaban como favorito y el aparente apoyo masivo de los potenciales electores, no consiguió conquistar ciertos sectores sociales todavía recalcitrantes a su mensaje. Se presentó en la campaña electoral como la única alternativa para salvar el país del "caos" creado por el gobierno de transición pero el veredicto de las urnas fue cruel a pesar de los 46 escaños cosechados. Su derrota fue muy amarga, y aún más al ser superado por Al Istiqlal, un partido tradicionalista, monárquico y conservador que predica el mismo mensaje basado en la moral religiosa. El electorado de ese partido es, desde la independencia, fiel a la doctrina conservadora elaborada por su fundador, Alál Fasí (1910-1974) desde los años 40 para abanderar la defensa de los fundamentos de la cultura arábigoislámica y la lucha contra el colonialismo. Su nombre está además asociado al nacionalismo ${ }^{12}$.

La USFP, partido que dirigió la oposición a Hasán II durante 40 años y el primer gobierno de transición (1998-2002), ha sido el gran perdedor. Los militantes socialistas y la clase obrera no le perdonaron la participación en un gobierno encabezado por un Primer Ministro tecnócrata, Drís Yetú, siendo la fuerza política más votada en las elecciones de septiembre de 2002. En definitiva, no consiguió preservar su mayoría sociológica en sus tradicionales feudos urbanos y distritos con predominio residencial de obreros. 
Al contrario, las otras formaciones (MP, RNI, UC) $)^{13}$ mejoraron su representación parlamentaria gracias a los votos de las zonas rurales donde los notables gozan aún de la notoriedad, del respeto y de la pleitesía de parte de la población. Cómo son dueños del ganado, de los terrenos y de los que los cultivan, las familias de estos notables gestionan sus latifundios como si fueran microestados. Los diputados elegidos en las circunscripciones rurales representarían el $50 \%$ de la Cámara Baja pero son en general afines a la doctrina oficial. La Monarquía, para ellos, es el sistema más adecuado para atender las expectativas de la sociedad y garantizar la seguridad de la ciudadanía, la estabilidad del país, y, el sistema de economía liberal afianzado durante el reinado de Hasán II.

\section{LA PREEMINENCIA DE LOS MINISTERIOS DE SOBERANÍA}

Abès Fasí dirige el vigésimo noveno gobierno desde la formación del primer gabinete de Marruecos independiente, que presidió M'Barek Bekay en 1955. Es un gobierno que ratifica la continuidad de la antigua coalición gubernamental presidida por el tecnócrata Drís Yetú, con los mismos aliados de ayer (Istiqlal, USFP, RNI, PPS). Es una unión "contra natura" que se presenta como "una sopa de siglas" donde cada partido lleva un disfraz ideológico distinto: Al Istiqlal (nacionalista conservador), USFP (social demócrata), Agrupación Nacional de los Independientes (notables, empresarios, intelectuales de centro derecha), Partido del Progreso y del Socialismo (comunista monárquico). Por espíritu de solidaridad, todas estas formaciones se someten a la disciplina dentro del gobierno y a un código de conducta encaminado a aplicar el programa del Primer Ministro, sin posibilidad de defender sus siglas ideológicas ni aprovechar para hacer cumplir las promesas hechas en campañas electorales (Duverger, 1970). Es una reedición del gobierno Yetú constituido por ministerios técnicos y sociales sin ninguna posibilidad de competir con los ministerios de soberanía (Relaciones Exteriores, Interior, Educación, Defensa, Asuntos religiosos, Comunicación). Por formar exclusivamente parte del dominio real, estos departamentos son los que se encargan del diseño de la política nacional. El propio monarca está rodeado de un Gabinete real, un nutrido equipo de "consejeros reales"14 que constituyen el "gobierno en la sombra" además de una multitud de directores generales de instituciones nacionales, nombrados directamente por el soberano ${ }^{15}$. En este caso, la función del Primer Ministro queda limitada a la coordinación de las acciones de los ministros para la aplicación de las "Altas Instrucciones de Su Majestad"". Según el art. 29 de la Constitución de Marruecos, "El Rey ejercerá por Dahir ${ }^{17}$ los poderes que le están expresamente atribuidos por la Constitución. Los dahíres serán refrendados por el Primer Ministro". Como Marruecos es una "monarquía ejecutiva" 18 , la mayor parte de las decisiones de gran calado escapan de las manos del primer ministro de manera que sus atribuciones se reducen al fin y al cabo a 
unas funciones subsidiarias ${ }^{19}$. Durante la campaña electoral, los partidos de izquierdas prometían la lucha por una reforma de la Constitución para reducir las atribuciones del Rey y dotar la institución del Primer Ministro de un verdadero poder ejecutivo. Esta actitud fue precedida, hace casi 50 años $^{20}$, de las primeras exigencias hechas por los socialistas cuando Mehdi Ben Barka ${ }^{21}$ reclamaba una Asamblea Constituyente que sería apta para elaborar la Carta Magna e introducir una verdadera separación de los poderes. Tal proyecto hubiera dado al primer ministro una dimensión correspondiente a un régimen de monarquía parlamentaria. La actitud de Ben Barka, que rechazaba un régimen de corte patriarcal, provocó el divorcio total entre los socialistas y el Palacio, cuarenta "años de plomo",22, un enorme retraso socioeconómico y una parálisis de las instituciones constitucionales. El gobierno de alternancia, como pieza clave en el proceso de transición política inaugurado en 1998 con Abderrahman Yusufíi ${ }^{23}$, debía en principio conducir a la democratización del Régimen. Fracasó Yusufí en la aplicación de su programa y en su cometido por falta de coordinación en el seno de su gobierno, la intromisión de los "consejeros del Rey" en su labor y por el sorprendente fortalecimiento de los poderes de la monarquía después de la entronización de Mohamed VI ${ }^{24}$.

Para que el estatuto del Primer Ministro en el sistema político marroquí tenga un contenido más concreto, señalamos tres tendencias que están en el origen del actual debate en Marruecos sobre la reforma de la Constitución:

La primera tendencia, conservadora, formada por Al Istiqlal, el Movimiento Popular, la Unión Constitucional o la agrupación Nacional de los Independientes, defiende el statu quo. Para esta corriente, el Rey debe salvaguardar la totalidad de sus atribuciones debido a la falta de madurez del pueblo ${ }^{25}$ y las potenciales amenazas contra la seguridad del Estado ${ }^{26}$. Sin embargo, esta tendencia sugiere que el Rey reduzca el número de carteras en el gobierno, autorice la supresión de la Cámara Alta ${ }^{27}$, disminuya el número de diputados de la Cámara Baja y atribuya prioridad a los sectores sociales. No se declara contraria a una reforma de la Constitución pero considera que sería oportuno posponer este proyecto para no comprometer la estabilidad del país.

La segunda tendencia, animada sobre todo por los partidos de izquierdas en el poder (USFP y PPS), prefiere abordar el tema con matices. Sostiene un equitativo reparto de atribuciones sin despojar al Rey de sus poderes con un fuerte Primer Ministro y un Parlamento que goce de más margen de maniobra. En este caso, sería necesario revisar algunas leyes relacionadas con el mapa electoral, la ley de partidos, y de paso, cambiar los artículos de la Constitución que otorgan al monarca el título de persona sagrada y prohíben comentar sus discursos ${ }^{28}$.

Una tercera tendencia, animada por los partidos de izquierdas en la oposición (La Vía Democrática, Partido de la Vanguardia, Unión Socialista Unificada) y la Asociación de Defensa de los Derechos Humanos (sobre todo), opta claramente por la total reforma de la Constitución para eliminar la bicefalia 
del poder ejecutivo (Rey/Primer Ministro). Aboga por la atribución del poder a los representantes del pueblo en una monarquía parlamentaria en la que el "Rey reina pero no gobierna". En estas condiciones, el monarca tendría el mismo estatuto que Juan Carlos I de España. El Primer Ministro sería el único Jefe del Ejecutivo y podría acudir al Rey cuando se tratase de cuestiones relacionadas con la seguridad nacional como la declaración de guerra, el tema del Sahara, las alianzas regionales e internacionales o temas religiosos debido a su estatuto de Comendador de Creyentes $^{29}$. Únicamente en estas condiciones, el gobierno marroquí sería un órgano coherente, eficaz y preparado para garantizar, para todos, un digno empleo, una salubre vivienda y un justo reparto de la riqueza nacional.

El futuro político de Marruecos depende en realidad de un gobierno capaz de instaurar un talento renovador basado en la creación de nuevas reglas de juego e instituciones independientes que regularían la relación entre el Ejecutivo y el Palacio, entre ciudadanos y administración, y, la revaloración del servicio público. En las negociaciones de los pactos para la formación de su gobierno, Abès Fasí se estrelló contra el alto número de carteras ministeriales exigidas por sus aliados como moneda de cambio por su apoyo ${ }^{30}$. Lamentablemente, la batalla por los escaños eclipsó la imagen sobria, equilibrada y prometedora que debía dar un gobierno en perspectiva de afrontar los futuros retos, estar a la altura de las preocupaciones de la población y exigir menos implicación de la monarquía en la gestión de los asuntos públicos. La realidad económica del país y las finanzas del Estado no permiten soportar el peso de un gobierno plagado de decenas de miembros $^{31}$. En las democracias occidentales, que disponen de más recursos y estabilidad política, los gabinetes son más reducidos y superan raras veces los 20 ministros para garantizar la cohesión entre sus miembros y la eficacia de sus acciones $^{32}$.

La alta abstención en las urnas, en los últimos comicios, es un claro mensaje que todos los actores políticos, e incluso el Palacio, deben descifrar para entender (o captar) el malestar del 63\% de los marroquíes que no acudieron a las urnas, el $18 \%$ de los votos nulos y los cinco millones de jóvenes que ni siquiera se acercaron a los ayuntamientos para inscribirse en el censo electoral. En principio, el proceso de transición, iniciado en la primavera de 1998, debía dejar paso a las instituciones democráticas y acabar con el "antiguo sistema" del Majzen, donde ningún órgano elegido asume realmente sus funciones ${ }^{33}$. El principal reto de cualquier Primer Ministro en Marruecos es recuperar la esperanza de encarrilar el país por la senda de la democracia, empezando por la reforma de la Constitución y la lucha contra el nepotismo, la corrupción institucionalizada y los abusos de poder. El actual gobierno que dirige Al Fasí traduce la voluntad de Mohamed VI de mantener intacta la antigua coalición creada a base del consenso y del respeto de los compromisos concluidos entre el Palacio y los partidos en la época de Hasán II. La novedad reside en el advenimiento de una nueva oposición dirigida por el Partido de la Justicia y del desarrollo (PJD: islamista) con el objetivo de desgastar 
la corriente islamista y agotar su discurso. Los aliados en la coalición ${ }^{34}$ cuentan con 16 ministros de sus filas que mantienen sus carteras, lo que corrobora el principio de continuidad exigido por el Rey. Otras siete carteras fueron atribuidas a independientes (designados por el Palacio) y otras siete más forman parte del dominio de los ministerios de soberanía. Este concepto está en flagrante contradicción con la práctica democrática que privilegia la lucha política y el veredicto de las urnas que representa la voluntad popular. Finalmente se optó por la lógica del consenso en la búsqueda de un gabinete formado por militantes de partidos domesticados, tecnócratas y candidatos del Palacio, unos elementos que no tienen en común ni referencia ideológica ni programa político común. La lectura del art. 24 de la Constitución ${ }^{35}$ que otorga al Rey la prerrogativa de nombrar al Primer Ministro, permite al final admitir que el actual gobierno está formado en su totalidad por "ministerios de soberanía". Hasta su entrada en el gobierno de alternancia en la época de Hasán II, los partidos de oposición (USFP, PPS, Istiqlal) rechazaban tajantemente la existencia de ministerios de soberanía y estratégicos que escapan del control del Primer Ministro. Los mismos partidos, actualmente miembros de la coalición, consienten esta fórmula como si fuera una práctica constitucional lo que demuestra la pérdida de su popularidad, el oportunismo de sus líderes y el monopolio de la iniciativa política por el Palacio.

Asistimos en la actual legislatura al nacimiento de un "gobierno de soberanía", de manera que todos los partidos aparentan ser domesticados y que los ministros son meros funcionarios al servicio del Palacio y del gabinete real. Consciente de esta realidad, los partidos en el poder admiten que su gobierno está en sintonía con la doctrina continuista del monarca que no está escrita en la Constitución. Son los consejeros del Rey los que se encargan del diseño de la estructura del gobierno, del reparto de las carteras entre los partidos y de la delimitación de las competencias de los ministros tecnócratas ${ }^{36}$. El Primer Ministro se limitó, al final, a avalar la lista de los "ministrables" y encabezar la ritual foto de familia de su gobierno.

Como los arts. 25 y 66 de la Constitución atribuyen al Rey competencias ejecutivas, la institución del Primer Ministro se reduce a un cargo honorífico y despojada de su estatuto de Jefe del Ejecutivo ${ }^{37}$. Sometido a tales condiciones, el gobierno tiene la obligación de elaborar un programa político que se ajuste a las líneas maestras trazadas por el Rey, las prioridades ideadas por el gabinete real, además de coordinar los programas sociales elaborados por los cuatro partidos miembros de la coalición.

\section{CONCLUSIÓN}

Marruecos, que ha despreciado la oportunidad de afianzar la transición democrática en un plazo tolerable, acaba de descubrir un nuevo panorama político 
cuyos actores son una elite cansada, unos partidos domesticados, erosionados y envejecidos y una oposición aseada y marginada en cualquier debate sobre el futuro del país. El largo periodo de transición (1998-2008) se ha quedado corto para que la elite política pueda sacar al país de la apatía e introducir nuevas reglas de juego en las que sean bien limitadas las funciones de cada institución: el Parlamento legisla, el Gobierno ejerce el Poder Ejecutivo y la monarquía asume su papel natural de arbitro. Otros países, como España, Portugal, Argentina o las exdemocracias socialistas de la Europa del Este superaron con éxito la transición democrática y en unos plazos cortos. Marruecos tendrá que aceptar la dialéctica de la derrota constitucional hasta la emergencia de una nueva generación de políticos e intelectuales preparados para liberarse del trauma del pasado, y, asumir las exigencias del cambio.

\section{NOTAS}

1. BENCHEMSI, A. (2007): «Le pari du roi », (La puesta del rey) en Tel Quel, 22-28. septiembre: 3. Disponible en internet: http://www.telquel-online.com/290/edito_290.shtml Consulta: 4 abril 2008]

${ }^{2}$ Véase el Artículo 19 de la Constitución de Marruecos: El Rey, Amir Al Muminin, Máximo Representante de la Nación, Símbolo de su unidad. Garante de la permanencia y de la continuidad del Estado, vela por el respeto al Islam y a la Constitución. Es el protector de los derechos y libertades de los ciudadanos, grupos sociales y colectividades. Garantiza la independencia de la Nación y la integridad territorial del Reino dentro de sus auténticas fronteras.

${ }^{3}$ Además del Código de prensa (promulgado en 1958 y modificado en 2003), existen otros textos legislativos que consideran la monarquía como institución sagrada. Citamos el Estatuto del Periodista Profesional (1958) o el Código de las Libertades Públicas (1958).

${ }^{4}$ Murieron 45 personas, cinco españoles entre ellos, en cinco atentados cometidos en cinco sitios distintos de Casablanca. El más sangriento tuvo lugar en el restaurante Casa de España

${ }^{5}$ Proliferan en las distintas regiones de Marruecos numerosas cofradías religiosas (o zauias) de origen místico que predican un Islam popular, la solidaridad en seno de la comunidad y la lucha contra las herejías.

6 Véase Ministère de l'Intérieur du Maroc, Elections législatives 2007, en http://www.elections.gov.ma/ [Consulta : 6 abril 2008].

${ }^{7}$ Artículo 60.- El Gobierno será responsable ante el Rey y ante el Parlamento. Tras el nombramiento del Gobierno por el Rey, el Primer Ministro se personará ante cada una de las Cámaras y expondrá el programa que pretende aplicar. Este programa tendrá que hacer resaltar las líneas directrices de la acción que el Gobierno pretende llevar a cabo en los diferentes sectores de la actividad nacional y particularmente en los ámbitos relacionados con la política económica, social, cultural y exterior. Este programa será debatido en el seno de cada una de las dos Cámaras. En la Cámara de los representantes será seguido por un voto en las condiciones previstas en el artículo 75 y con el efecto contemplado en el último párrafo de este mismo artículo. 
8 «De nombreux défis à relever pour sortir du sous-développement», en PopulationData.net, 23 octobre 2007, disponible en Internet: http://www.populationdata.net/pays/afrique/maroc.php (Consulta: 12 marzo 2007).

9 ARIRI, A. (2007): “"التقطيع الانتخابي ساعد على التدكم في الذريطة السياسية:" (el diseño del sistema electoral ayudó al ministerio del Interior en el control del mapa político), en الوطن الآن (Alwatan $\mathrm{Al} \quad \mathrm{An}$ ), $14-20$ septiembre: $14 . \quad$ Disponible en Internet: http://www.alwatan.press.ma/BrowseArticles.aspx?CatID=1\&NumID=257. [Consulta15 abril 2008]

${ }^{10}$ Ex compañero de clase de Mohamed VI y hombre fuerte del círculo más cercano del monarca, Fuad Ali Hima, cuya lista electoral ganó en los comicios del 7 de septiembre de 2007 tres escaños bajo la sigla "Sin afiliación política", consiguió formar un grupo parlamentario de 36 diputados al inicio de la legislatura, en octubre de 2007, gracias a un proceso de recuperación de diputados fugados de sus respectivos grupos.

${ }_{12}^{11}$ Se trata de la RTM y 2M, dos cadenas públicas.

12 ( hizb al-istiqlāl) o Partido de la Independencia. Ha sido siempre fiel a la monarquía en distintas circunstancias de la historia política de Marruecos a pesar de los roces con el rey Hasán II. Defiende el concepto tradicional de la familia, el estricto respeto de la chari'a (doctrina musulmana) y el sistema sucesorio en el poder. Se opone a la reforma del estatuto actual de la monarquía.

13 Los tres partidos son considerados como "partidos de servicio" o "partidos administrativos" creados por el ministerio del Interior en las zonas rurales y dentro de los círculos empresariales y sindicales. El objetivo del Régimen era romper la hegemonía de los partidos tradicionales, que participaron en la lucha por la independencia, en sus zonas de influencia.

${ }^{14}$ Los consejeros reales aparecen, en el protocolo, antes de los ministros.

${ }^{15}$ Señalamos, entre otros, los Consejos Superiores, Oficinas, Fundaciones, Empresas públicas, Federaciones Reales de Deportes, etc.

${ }^{16}$ Terminología ampliamente usada en los medios de comunicación públicos y discursos oficiales para recordar la preeminencia de las decisiones tomadas por el monarca o en su nombre.

${ }^{17}$ Decreto Real.

18 "Los marroquíes quieren una monarquía fuerte, democrática y ejecutiva. En nuestro caso el rey no se conforma con reinar. Además, el rey tiene una legitimidad religiosa porque es el Comendador de los Creyentes", Mohamed VI (2001): en Le Figaro, 04 septiembre: 2.

${ }^{19}$ Art. 29: El Rey ejercerá por Dahir los poderes que le están expresamente atribuidos por la Constitución. Los dahíres serán refrendados por el Primer Ministro; Art. 30: Corresponderá al Rey el mando supremo de las Fuerzas Armadas Reales. El Rey nombrará en las funciones civiles y militares y podrá delegar este derecho; Art. 31: El Rey acreditará los embajadores ante las potencias extranjeras y organismos internacionales. Los embajadores o representantes de los organismos internacionales se acreditarán ante él. El Rey firmará y ratificará los tratados. No obstante, los tratados que comprometen las finanzas del Estado no podrán ser ratificados sin aprobación previa por ley. Los tratados susceptibles de estar en contradicción con lo dispuesto en la Constitución serán aprobados en la forma prevista para la reforma constitucional; Art. 32: El Rey presidirá el Consejo Superior de la Magistratura, el Consejo Superior de la Enseñanza y el Consejo Superior de 
la Promoción Nacional y del plan; Art. 33: El Rey nombrará a los Magistrados según lo dispuesto en el artículo 84; Art. 34: El Rey ejercerá el derecho de gracia.

${ }^{20}$ Desde la independencia y a principios de los años 60 .

${ }^{21}$ Mehdi Ben Barka (1920-1965), político marroquí, activista por la independencia y más tarde disidente del régimen de Hasán II, cofundador de los partidos políticos Istiqlal y UNFP y figura dirigente del movimiento tercermundista. Su secuestro y asesinato, en extrañas circunstancias en París en octubre de 1965, aparentemente a manos de los servicios secretos marroquíes y franceses, es uno de los episodios más enigmáticos del periodo de la historia de Marruecos conocido como " años de plomo".

${ }^{22}$ Términos utilizados para designar el reino de Hasán II marcado por una implacable represión de los intelectuales, políticos y sindicalistas de izquierda.

${ }^{23}$ Amigo de Ben Barka, prefirió auto exiliarse para huir de la represión en los años 60 . Le llamó Hasán II para dirigir el primer gobierno de alternancia.

${ }^{24}$ Hasán II murió el 23 de julio de 1999.

${ }^{25}$ Es la misma postura que defendía Hasán II, a principios de los años 60, para justificar su rechazo de una monarquía parlamentaria en Marruecos como lo reivindicaba la oposición socialista.

26 Citamos la oposición a la instauración de un sistema federal respetando las particularidades étnicas y lingüísticas de las distintas regiones (árabes, beréberes y saharuíes), la emergencia del islamismo y el peligro de golpe de Estado.

${ }^{27}$ Cámara de los consejeros elegidos indirectamente por las cámaras profesionales y juntas municipales y prefectorales. Está constituida sobre todo de notables y empresarios.

${ }^{28}$ El Ministerio del Interior ordenó, el 4 de agosto de 2007, el secuestro tanto del semanal en árabe Nichane como de su revista gemela en francés, Tel Quel (Tal Cual) que publicó informaciones que suponieran una falta de respeto al rey Mohamed VI. En un comunicado, el primer ministro, Drís Yetú, afirmó que esta decisión se tomó a raíz de la publicación de un editorial y de un conjunto de artículos con expresiones que "van contra las costumbres y la moral pública, ofenden los sentimientos de los musulmanes y constituyen un incumplimiento al respeto debido a Su Majestad el Rey". En realidad, Nichane comentó en su editorial un discurso real en el dialecto marroquí sobre el balance de su gestión desde su entronización en julio de 1999. Véase el manifiesto de los intelectuales por el respeto de las libertades individuales en http://www.telquel-online.com/318/appel.shtml [Consulta: 6 abril 2008].

${ }^{29}$ Un título introducido por Hasán II como alta jerarquía religiosa en el país en el intento de monopolizar el campo religioso ante el auge de las cofradías y movimientos islamistas. Mohamed VI lo conservó y lo usó a la hora de decidir la reforma del Código de la Familia ante las presiones ejercidas por los partidos de izquierdas.

${ }^{30} \mathrm{El}$ primer gabinete de Yusufí, formado en 1998, contaba 39 miembros entre ministros y secretarios de Estado.

${ }^{31} \mathrm{El}$ actual gabinete está formado por 34 miembros.

32 El actual gobierno en Francia cuenta con sólo 15 ministros. Se puede consultar: http://www.bismi.net/articlelecture.php?id=1145

33 El término está asociado a un modo arcaico y hermético de gobernar, opuesto a la democracia formal de las instituciones marroquíes. Aunque los contornos del Majzen son vagos, el gobierno en sí mismo no es considerado parte de él sino instrumento suyo. El 
Majzen por lo general coopta a sus miembros utilizando sus propias redes de amistades e influencia. Con frecuencia la pertenencia al Majzen es hereditaria de modo que existen familias majzenianas que llevan siglos al servicio del Palacio. Dentro de ellas, se nombran ministros, embajadores, altos cargos de la administración, rectores de universidades, consejeros reales, etc. Citamos entre otras Alaui, Fasí, Benani, Benyelún, Benslimane, Guesús, Tazi, Bensuda, El Kohen, Sebti, El Mokri, Lahlu, Beráda, Sqalí, Lazrak, Ketani. Para más detalles, véase: "Les fassis", en Tel Quel (2004), 22-28 febrero. Disponible en Internet: http://www.telquel-online.com/124/couverture_124_1.shtml [Consulta: 6 abril 2008].

${ }^{34}$ Los partidos de obediencia popular miembros de la coalición saliente (Movimiento Popular y Movimiento Nacional Popular), fueron excluidos en el último momento del gabinete de Fasí por rechazar las carteras que les propusieron los consejeros del Rey.

${ }^{35}$ Art. 24: El Rey nombrará al Primer Ministro. A propuesta del Primer Ministro, nombrará a los demás miembros del Gobierno. Podrá poner fin a sus funciones. Pone fin a las funciones del Gobierno, sea por su propia iniciativa, sea a consecuencia de la dimisión del Gobierno.

${ }^{36}$ Dos consejeros reales, Abdelaziz Meziane Belfkih y Mohamed Moatassim, dirigieron el proceso de negociaciones con los partidos en vísperas de la formación del gobierno de Fasí, después de las elecciones del 7 de septiembre de 2007.

${ }^{37}$ Art. 25: El Rey preside el Consejo de Ministros. Art. 66: El Consejo de Ministros examina, antes de cualquier decisión: las cuestiones relativas a la política general del Estado, la proclamación del estado de sitio, la declaración de guerra, la puesta en juego de la responsabilidad del Gobierno ante la Cámara de los Representantes, los proyectos de ley, antes de su remisión a la mesa de cualquiera de las dos Cámaras, los decretos reglamentarios, los decretos referidos en los Art. 40, 41, 45 y 55 de esta Constitución, el proyecto de plan, el proyecto de reforma constitucional.

\section{BIBLIOGRAFÍA}

BEAUGÉ, F. (2007): “Au Maroc, les élections législatives ne suscitent guère l'enthousiasme", Le Monde, 07 de septiembre. Disponible en Internet: http:/www.lemonde.fr/web/panorama/0,11-0@2-3212,32-952698,0.html [Consulta: 3 abril 2008]

BLANCH, J.M. y MUÑOZ, J.M. (1998): “Ideología Política”, en Psicología Política. Madrid, Pirámide,

BURLOT, J. (1990): La civilisation islamique, Paris, Hachette.

CASTRO, C. (2008): Relato electoral de España (1977-2007), Barcelona, Institut de Ciències Politiques i Socials.

DUVERGER, M. (1970), Institutions politiques et droit constitutionnel, Paris, Gallimard.

ÉTIENNE, B. (2005): ¿Qué inquieta del Islam?, Barcelona, Ediciones Bellatera.

JAMAÏ, A. (2002): "La gauche gouvernementale piégée au Maroc", Le Monde Diplomatique, septiembre. Disponible en internet: http://www.mondediplomatique.fr/2002/09/JAMAI/16864 [Consulta: 31 marzo 2008] 
LEVEAU, R. (1976): Le Fellah Marocain Défenseur du Trône, Paris, Presses de la Fondation Nationale des Sciences Politiques.

LÓPEZ GARCÍA, B. (2000): Marruecos político: cuarenta años de procesos electorales (1960-2000), Madrid, CIS.

MAQUIAVELO, N. (1973): El príncipe, Madrid, Espasa-Calpe.

MONTABES PEREIRA, J. (1999): Las otras elecciones, Madrid, AECI.

NOELLE-NEUMANN, E. (1995): La espiral del silencio, Barcelona, Paidós.

PAREJO FERNÁNDEZ, M. A. (1999): Las elites politicas marroquíes, Madrid, AECI.

REZETTE, R. (1955): Les partis politiques marocains, Paris, Armand Colin.

ROQUE, M.A. (2002): La sociedad civil en Marruecos, Barcelona, Icaria.

ROSANVALLON, P. (1998): Le peuple introuvable, Histoire de la représentation démocratique en France, Paris, Gallimard.

ROUSSEAU, J. J. (2001): El contrato social, Madrid, Espasa.

TOZY, M. (2000): Monarquía e Islam político en Marruecos, Barcelona, Bellaterra.

TUQUOI, J.P. (2001): Le dernier roi: crépuscule d'une dynastie, Paris, Grasset.

VERMEREN, (2002): Marruecos en transición, Granada, Almed.

VIDAL, C. (2006): España frente al Islam, Madrid, La Esfera de los libros, Madrid.

VOLKOFF, V. (2002): Pourquoi je suis moyennement démocrate, París, Rocher.

WATERBURY, J. (1975): Le Commandeur des croyants. La monarchie marocaine et son élite, Paris, PUF.

\section{Breve currículo:}

\section{Mohamed Boundi Boundi}

Doctor en Sociología de la comunicación y licenciado en periodismo. Ha sido corresponsal de la agencia Maghreb Árabe Presse en España durante los años 1987 a 2004. Actualmente ejerce como investigador en temas relacionados con los sistemas políticos, la inmigración, el entramado de relaciones hispano-marroquíes, la sociología del mundo arábigo-musulmán y los medios de comunicación de masas. Colabora como analista de la actualidad hispanomarroquí en diversos periódicos digitales. 